\title{
Effectiveness of Interorganizational Relations in the Regional Tourist and Recreational Network (Empirical Study Using a Fuzzy Model)
}

\author{
N. Rubtsova ${ }^{1, *}$, K. Solodukhin ${ }^{2}$ \\ ${ }^{1}$ Baikal State University, Irkutsk, Russia \\ ${ }^{2}$ Vladivostok State University of Economics and Service, Vladivostok, Russia \\ ${ }^{*}$ Corresponding author. Email: runatasha21@yandex.ru
}

\begin{abstract}
The article is dedicated to study of the effectiveness of interorganizational relations in the regional tourist and recreational network. The study methodology is based on a combination of systemic, functional and targeted approaches, the theory of fuzzy sets. A multilevel system of indicators of the interorganizational interaction effectiveness is offered. A methodological toolkit for assessing the effectiveness of interorganizational relations in the network using the fuzzy model has been developed, its approbation is provided on the example of a large tourist and recreational network of the Irkutsk region. The results obtained indicate that in the long term, the effectiveness of interorganizational relations increases - there is a pronounced positive dynamics of various indicators characterizing the network agents' satisfaction. It is shown that collaboration leads to a partial loss of the power of influence of its individual members in relation to the network as a whole, but these losses are compensated by the benefits obtained as a result of increasing the efficiency of interorganizational interaction, determined by means of monetary and non-monetary indicators.
\end{abstract}

Keywords: effectiveness, network, region, alliance, collaboration, inter-organizational relationship.

\section{INTRODUCTION}

To assess the effectiveness of network interfirm relations, to date, a significant number of models and methods have been offered using both individual indicators and multi-parameter scales and systems [1-6]. Wherein, the most frequently measured characteristics are trust and satisfaction, loyalty, and intention to continue the relationship. Summarizing the developments of domestic and foreign researchers, it can be stated that effectiveness of interfirm interaction is a complex category that includes a significant number of various characteristics, which requires the use of a systematic approach to its assessment. Also, among the available developments, there is the functional approach offered by A. Walter et al. [7] who interprets the effectiveness of interorganizational interaction through a number of direct and indirect functions that reflect various aspects of the relationships value. The functional approach provides, in our opinion, a wide range of possibilities for its use. Definition and description of the functions of relations can serve as a basis for specifying the goals of developing interorganizational relations, justifying indicators for assessing the IOR effectiveness. Considering the ideas of goal-oriented, systemic and functional approaches, the authors have formed a list of specific functions, goals and indicators for assessing the effectiveness of inter-organizational relations in the tourist and recreational network (Table 1), as well as a conceptual model (provided in [8]). The indicators characterizing the effectiveness of interorganizational interaction in the tourist and recreational network, in the list we offered (Table 1), were selected in accordance with the logic of implementation of the functions provided and achievement of the corresponding goals regarding the relations development. The provided functions, goals and indicators of interorganizational relations seem to make it possible to form the concept of "the effectiveness of interorganizational interaction in the tourist and recreational network" that is a complex characteristic that determines the mutual orientation of the partners of the sustainable competitive advantages. 
Table 1. Relationship functions and examples of indicators characterizing the effectiveness of inter-organizational interaction in the tourist and recreational network

\begin{tabular}{|c|c|c|c|}
\hline $\begin{array}{l}\text { Function of } \\
\text { relations }\end{array}$ & $\begin{array}{c}\text { Goal of } \\
\text { relations development }\end{array}$ & Indicators & $\begin{array}{l}\text { Nature of the } \\
\text { goal and } \\
\text { indicators }\end{array}$ \\
\hline $\begin{array}{l}\text { Receiving the } \\
\text { profit }\end{array}$ & $\begin{array}{l}\text { Maximizing } \\
\text { the profit }\end{array}$ & $\begin{array}{l}\text { Net profit } \\
\text { Profitability (return on invested and related } \\
\text { capital) }\end{array}$ & Monetary \\
\hline $\begin{array}{l}\text { Market } \\
\text { development }\end{array}$ & Expanding the market share & $\begin{array}{l}\text { Marketing event costs } \\
\text { Expanding the customer base }\end{array}$ & Monetary \\
\hline $\begin{array}{l}\text { Development } \\
\text { of } \\
\text { personnel }\end{array}$ & $\begin{array}{l}\text { Reducing the costs for personnel } \\
\text { management }\end{array}$ & Search, training and personnel adaptation costs & Monetary \\
\hline $\begin{array}{l}\text { Development } \\
\text { of } \\
\text { management }\end{array}$ & Reducing the management costs & $\begin{array}{l}\text { Costs for performing the management functions } \\
\text { (access to information about customers, } \\
\text { competitors, new products, new needs) }\end{array}$ & Monetary \\
\hline $\begin{array}{l}\text { Resource } \\
\text { exchange }\end{array}$ & $\begin{array}{l}\text { Formation of a resource base to } \\
\text { achieve goals, obtaining resources of } \\
\text { the required quantity and quality }\end{array}$ & $\begin{array}{l}\text { Satisfaction with participation in the alliance } \\
\text { Satisfaction with resource interaction with } \\
\text { partners }\end{array}$ & Non-monetary \\
\hline Market power & Increasing the market power & $\begin{array}{l}\text { Strength of the mutual influence of the alliance } \\
\text { as a whole and its individual members } \\
\text { Strength of mutual influence between individual } \\
\text { members of the alliance }\end{array}$ & Non-monetary \\
\hline $\begin{array}{l}\text { Development } \\
\text { of } \\
\text { innovations }\end{array}$ & Creation of innovations & $\begin{array}{l}\text { Joint development of tourism products } \\
\text { Reducing time of development and start of new } \\
\text { tourism products }\end{array}$ & Non-monetary \\
\hline $\begin{array}{l}\text { Improving the } \\
\text { quality } \\
\text { relations }\end{array}$ & $\begin{array}{l}\text { Increased commitment, satisfaction } \\
\text { and trust in partners }\end{array}$ & $\begin{array}{l}\text { Reliability of partners } \\
\text { Stable relationship } \\
\text { Long-term relationship } \\
\text { Equality of partners } \\
\text { Fairness of relationship } \\
\text { Personalization (flexibility) of relations }\end{array}$ & Non-monetary \\
\hline
\end{tabular}

\section{MATERIALS AND METHODS}

Assessment of non-monetary characteristics of interorganizational relations that are fuzzy and vague concepts requires the subjective (expert) knowledge. Expert assessments of the values of these characteristics are strongly influenced by the expert's judgments, perceptions and emotions. Wherein, it is easier for an expert to give qualitative (verbal) assessments of the characteristics of relations than quantitative ones. In addition, the quantitative assessment of the monetary characteristics of interorganizational relations is also fraught with significant difficulties. Often, in practice, obtaining reliable and accurate information about the values of monetary parameters and their changes is complicated by the unwillingness of companies included in the network to disclose real information about the value of costs, profits, profitability, and etc. In the absence of crisp numerical values of the characteristics of relations, it is advisable to operate with verbal expert assessments. Formalization of subjective knowledge about the monetary and non-monetary characteristics of interorganizational relations can be carried out using the fuzzy set theory tools. In this regard, we have developed the following fuzzy model for assessing the effectiveness of interorganizational relations.

Let's introduce the following fuzzy variables:
1. a degree of satisfaction of $i$-th agent $(i=\overline{1, K})$ with participation in the alliance at time $t(t=\overline{1, T})\left(S D_{i}^{t}\right)$;

2. a degree of satisfaction of the $i$-th agent with interaction with the $j$-th counterparty $(j=\overline{1, K})$ in the alliance at time $t\left(S D_{i j}^{t}\right)$;

3. an assessment of the expectations of the $i$-th agent at time $t$ in relation to changes in satisfaction at time $t+1$ ( $\left.\Delta S D_{i}^{t}\right)$

4. an assessment of the expectations of the $i$-th agent at time $t$ with respect to changes in satisfaction with interaction with the $j$-th counterparty at time $t+1\left(\Delta S D_{i j}^{t}\right.$ )

5. a degree of mutual influence of the alliance and the $i$-th agent at time $t\left(M I D_{i}^{t}\right)$;

6. a degree of mutual influence of the $i$-th and $j$-th agents at moment $t$ from the point of view of the $i$-th agent ( $\left.M I D_{i j}^{i t}\right)$;

7. an assessment of the expectations of the $i$-th agent at time $t$ with respect to changes in the degree of mutual influence with the alliance at time $t+1\left(\Delta M I D_{i}^{t}\right)$; 
8. an assessment of the expectations of the $i$-th agent at time $t$ with respect to changes in the degree of mutual influence with the $j$-th counterparty at time

$t+1\left(\Delta M I D_{i j}^{i t}\right)$

9. a profitability of $i$-th agent sales at time $t\left(P M_{i}^{t}\right)$;

10. a change in the profitability of the $i$-th agent sales at time $t$ in comparison with time $t-1\left(\Delta P M_{i}^{t}\right)$;

11. specific costs for training the personnel of the $i$-th agent at time $t\left(S T C_{i}^{t}\right)$;

12. a change in the specific costs of training the personnel of the $i$-th agent at time $t$ compared to time $t-1\left(\triangle S T C_{i}^{t}\right)$;

13. specific cost to the product advancement of the $i$-th agent at time $t\left(P P C_{i}^{t}\right)$;

14. a change in specific costs of promoting the product of the $i$-th agent at time $t$ compared to time $t-1\left(\triangle P P C_{i}^{t}\right)$;

15. unit cost to perform management functions $i$-th agent at the time $t\left(M F C_{i}^{t}\right)$;

16. a change in specific costs for performance of managerial functions of the $i$-th agent at time $t$ compared to time $t-1$ $\left({ }_{\triangle M F C_{i}^{t}}\right)$;

17. a fairness of relations in the alliance at time $t$ from the point of view of the $i$-th agent $\left(F R_{i}^{t}\right)$;

18. equivalence relations at time $t$ from the point of view of the $i$-th agent $\left(E Q R_{i}^{t}\right)$;

19. stability relations at time $t$ from the point of view of the $i$-th agent $\left(S T R_{i}^{t}\right)$

20. a reliability of the relationship at time $t$ from the point of view of the $i$-th agent $\left(R R_{i}^{t}\right)$;

21. the long-term relationships at time $t$ of the point of view of the $i$-th agent $\left(L R_{i}^{t}\right)$;

22. a personification of relations at moment $t$ from the point of view of the $i$-th agent $\left(P R_{i}^{t}\right)$.

Table 2-5 provides term sets of linguistic variables.

Table 2. Term sets of linguistic variables $S D_{i}^{t}, S D_{i j}^{t}$

\begin{tabular}{|l|c|}
\hline \multicolumn{1}{|c|}{ Variable value } & Membership function \\
\hline Completely dissatisfied (LL) & $(-5 ;-5 ;-4 ;-3)$ \\
\hline Significantly dissatisfied (L) & $(-4.5 ;-3.75 ;-2.25 ;-$ \\
& $1.5)$ \\
\hline Moderately dissatisfied (ML) & $(-3 ;-2.25 ;-0.75 ; 0)$ \\
\hline $\begin{array}{l}\text { Partly satisfied and partly } \\
\text { dissatisfied (M) }\end{array}$ & $(-1.5 ;-0.75 ; 0.75 ;$ \\
\hline Moderately satisfied (MH) & $(0 ; 0.75 ; 2.25 ; 3)$ \\
\hline Significantly satisfied (H) & $(1.5 ; 2.25 ; 3.75 ; 4.5)$ \\
\hline Completely satisfied (HH) & $(3 ; 4 ; 5 ; 5)$ \\
\hline
\end{tabular}

Table 3. Term sets of linguistic variables $\Delta S D_{i}^{t}, \Delta S D_{i j}^{t}$,

\begin{tabular}{|c|c|}
\hline Variable value & Membership function \\
\hline Will worsen dramatically $(\mathrm{NH})$ & $(-5 ;-5 ;-4 ;-3)$ \\
\hline Will worsen significantly (NM) & $(-4.5 ;-3.75 ;-2.25 ;-1.5)$ \\
\hline Will worsen slightly (NL) & $(-3 ;-2.25 ;-0.75 ; 0)$ \\
\hline Will not change (NE) & $(-1.5 ;-0.75 ; 0.75 ; 1.5)$ \\
\hline Will improve slightly (PL) & $(0 ; 0.75 ; 2.25 ; 3)$ \\
\hline Will improve significantly (PM) & $(1.5 ; 2.25 ; 3.75 ; 4.5)$ \\
\hline Will improve dramatically (PH) & $(3 ; 4 ; 5 ; 5)$ \\
\hline
\end{tabular}

Table 4. Term sets of linguistic variables $M I D_{i}^{t}, M I D_{i j}^{t}$ *

\begin{tabular}{|c|c|}
\hline Variable value & $\begin{array}{l}\text { Membership } \\
\text { function }\end{array}$ \\
\hline $\begin{array}{l}\text { Influence of the alliance (or counterparty) on } \\
\text { the agent is incomparably greater than } \\
\text { influence of the agent on the alliance (or } \\
\text { counterparty) }(\mathrm{CH})\end{array}$ & $(-5 ;-5 ;-4 ;-3)$ \\
\hline $\begin{array}{l}\text { Influence of the alliance (or counterparty) on } \\
\text { the agent is significantly greater than } \\
\text { influence of the agent on the alliance (or } \\
\text { counterparty) (CM) }\end{array}$ & $\begin{array}{c}(-4.5 ;-3.75 ;- \\
2.25 ;-1.5)\end{array}$ \\
\hline $\begin{array}{l}\text { Influence of the alliance (or counterparty) on } \\
\text { the agent is moderately greater than influence } \\
\text { of the agent on the alliance (or counterparty) } \\
\text { (CL) }\end{array}$ & $\begin{array}{c}(-3 ;-2.25 ;- \\
0.75 ; 0)\end{array}$ \\
\hline $\begin{array}{l}\text { The mutual influence of the agent and the } \\
\text { alliance (or counterparty) on each other is } \\
\text { approximately the same (NE) }\end{array}$ & $\begin{array}{c}(-1.5 ;-0.75 \\
0.75 ; 1.5)\end{array}$ \\
\hline $\begin{array}{l}\text { The agent's influence on the alliance (or } \\
\text { counterparty) is moderately greater than } \\
\text { influence of the alliance (or counterparty) on } \\
\text { the agent (SL) }\end{array}$ & $\begin{array}{c}(0 ; 0.75 ; 2.25 ; \\
3)\end{array}$ \\
\hline $\begin{array}{l}\text { The agent's influence on the alliance (or } \\
\text { counterparty) is significantly greater than } \\
\text { influence of the alliance (or counterparty) on } \\
\text { the agent (SM) }\end{array}$ & $\begin{array}{l}(1.5 ; 2.25 \\
3.75 ; 4.5)\end{array}$ \\
\hline $\begin{array}{l}\text { The agent's influence on the alliance (or } \\
\text { counterparty) is incomparably greater than } \\
\text { influence of the alliance (or counterparty) on } \\
\text { the agent (SH) }\end{array}$ & $(3 ; 4 ; 5 ; 5)$ \\
\hline
\end{tabular}

Table 5. Term sets of linguistic variables $P M_{i}^{t}, S T C_{i}^{t}$, $P P C_{i}^{t}, M F C_{i}^{t}, F R_{i}^{t}, E Q R_{i}^{t}, S T R_{i}^{t}, R R_{i}^{t}, L R_{i}^{t}, P R_{i}^{t}$

\begin{tabular}{|l|c|}
\hline \multicolumn{1}{|c|}{ Variable value } & Membership function \\
\hline High $(\mathrm{H})$ & $(7 ; 8 ; 10 ; 10)$ \\
\hline Above the average $(\mathrm{MH})$ & $(5 ; 6 ; 8 ; 9)$ \\
\hline Medium (M) & $(3 ; 4 ; 6 ; 7)$ \\
\hline Below the average (short) (ML) & $(1 ; 2 ; 4 ; 5)$ \\
\hline Low (L) & $(0 ; 1 ; 2 ; 3)$ \\
\hline Very low (LL) & $(0 ; 0 ; 1 ; 2)$ \\
\hline
\end{tabular}

We shall notice, that

$$
S D_{i}^{t+1}=S D_{i}^{t}+\Delta S D_{i}^{t}, S D_{i j}^{t+1}=S D_{i j}^{t}+\Delta S D_{i j}^{t}
$$




$$
\begin{aligned}
& M I D_{i}^{t+1}=M I D_{i}^{t}+\Delta M I D_{i}^{t}, M I D_{i j}^{i, t+1}=M I D_{i j}^{i t}+\Delta M I D_{i j}^{i t} \\
& P M_{i}^{t+1}=P M_{i}^{t}+\Delta P M_{i}^{t}, S T C_{i}^{t+1}=S T C_{i}^{t}+\Delta S T C_{i}^{t}, \\
& P P C_{i}^{t+1}=P P C_{i}^{t}+\Delta P P C_{i}^{t}, M F C_{i}^{t+1}=M F C_{i}^{t}+\Delta M F C_{i}^{t} .
\end{aligned}
$$

Let's introduce the variables:

23) a general $\left(O S D^{t}\right)$ and average $\left(A S D^{t}\right)$ degree of satisfaction of the alliance agents at time $t$;

24) a general $\left(T S D_{i}^{t}\right)$ and average $\left({ }_{A P S D_{i}^{t}}\right)$ degree of satisfaction of the $i$-th agent with interaction with counterparties at time $t$;

25) a general $\left(\overline{T S D}_{i}^{t}\right)$ and average $\left(\overline{A P S D}_{i}^{t}\right)$ degree of satisfaction of the counterparties with the interaction with the $i$-th agent at moment $t$

26) an average degree of mutual satisfaction of the alliance agents at time $t\left({ }_{A P S D^{t}}\right)$;

27) a general $\left(\right.$ OMID $\left.^{t}\right)$ and average $\left(A M I D^{t}\right)$ degree of influence of agents within the alliance at time $t$;

28) a degree of mutual influence of the $i$-th and $j$-th agents at moment $t\left({ }_{M I D_{i j}^{t}}\right)$;

29) a general $\left(T M I D_{i}^{t}\right)$ and average $\left(A M I D_{i}^{t}\right)$ degree of mutual influence of the $i$-th agent with counterparties within the alliance at time $t$;

30) a general $\left(O P M^{t}\right)$ and average $\left(A P M^{t}\right)$ profitability of agents sales at time $t$;

31) a general ( OSTC $\left.^{t}\right)$ and average $\left.\left({ }_{A S T C}\right)^{t}\right)$ agents costs for personnel training at time $t$;

32) a general $\left({ }_{O P P C^{t}}\right)$ and average $\left({ }_{A P P C^{t}}\right)$ costs of agents to promote the product at time $t$;

33) a general $\left(O M F C^{t}\right)$ and average $\left(A M F C^{t}\right)$ costs of agents to perform management functions at time $t$;

34 ) a degree of quality of relations of the $i$-th agent in the strategic alliance at time $t\left(R Q_{i}^{t}\right)$.

We will assume that

$$
\begin{aligned}
& O S D^{t}=\sum_{\mathrm{i}=1}^{K} S D_{i}^{t}, O M I D^{t}=\sum_{\mathrm{i}=1}^{K} M I D_{i}^{t}, O P M^{t}=\sum_{\mathrm{i}=1}^{K} P M_{i}^{t}, O S T C^{t}=\sum_{\mathrm{i}=1}^{K} S T C_{i}^{t}, \\
& O P P C^{t}=\sum_{\mathrm{i}=1}^{K} P P C_{i}^{t}, O M F C^{t}=\sum_{\mathrm{i}=1}^{K} M F C_{i}^{t}, O F R^{t}=\sum_{\mathrm{i}=1}^{K} F R_{i}^{t}, O E Q R^{t}=\sum_{\mathrm{i}=1}^{K} E Q R_{i}^{\prime} \\
& O S T R^{t}=\sum_{i=1}^{K} S T R_{i}^{t}, O R R^{t}=\sum_{i=1}^{K} R R_{i}^{t}, O L R^{t}=\sum_{\mathrm{i}=1}^{K} L R_{i}^{t}, O P R^{t}=\sum_{\mathrm{i}=1}^{K} P R_{i}^{t}, \\
& A S D^{t}=E\left(O S D^{t}\right), \quad A M I D^{t}=E\left(O M I D^{t}\right), A P M^{t}=E\left(O P M^{t}\right), \\
& A_{S T C}^{t}=E\left(O S T C^{t}\right), A P P C^{t}=E\left(O P P C^{t}\right), \\
& A M F C^{t}=E\left(O M F C^{t}\right), A F R^{t}=E\left(O F R^{t}\right), \\
& A E Q R^{t}=E\left(O E Q R^{t}\right), A S T R^{t}=E\left(O S T R^{t}\right), \\
& A R R^{t}=E\left(O R R^{t}\right), A L R^{t}=E\left(O L R^{t}\right), \\
& A P R^{t}=E\left(O P R^{t}\right) \\
& M I D_{i j}^{t}=0,5 \cdot\left(M I D_{i j}^{i t}-M I D_{i j}^{j t}\right), T M I D_{i}^{t}=\sum_{\mathrm{i}=1}^{K} M I D_{i j}^{t},(6) \\
& A M I D_{i}^{t}=E\left(T M I D_{i}^{t}\right) \text {, } \\
& T S D_{i}^{t}=\sum_{\mathrm{j}=1}^{K} S D_{i j}^{t}, \overline{T S D}_{i}^{t}=\sum_{\mathrm{i}=1}^{K} S D_{i j}^{t}, A P S D_{i}^{t}=E\left(T S D_{i}^{t}\right),(7) \\
& \overline{\operatorname{APSD}}_{i}^{t}=E\left(\overline{\operatorname{TSD}}_{i}^{t}\right) \text {, }
\end{aligned}
$$

$$
\begin{gathered}
A P S D^{t}=\sum_{\mathrm{i}=1}^{K}\left(A P S D_{i}^{t}+\overline{A P S D}_{i}^{t}\right), \\
A F R_{i}^{t}=E\left(F R_{i}^{t}\right), \\
A E Q R_{i}^{t}=E\left(E Q R_{i}^{t}\right), A S T R_{i}^{t}=E\left(S T R_{i}^{t}\right), \quad(9) \\
A R R_{i}^{t}=E\left(R R_{i}^{t}\right), A L R_{i}^{t}=E\left(L R_{i}^{t}\right), \\
A P R_{i}^{t}=E\left(P R_{i}^{t}\right), \\
R Q_{i}^{t}=F R_{i}^{t}+E Q R_{i}^{t}+S T R_{i}^{t}+R R_{i}^{t}+L R_{i}^{t}+P R_{i}^{t}, \\
A R Q_{i}^{t}=E\left(R Q_{i}^{t}\right), \\
R Q^{t}=\sum_{\mathrm{i}=1}^{K} R Q_{i}^{t}, A R Q^{t}=E\left(R Q^{t}\right) .
\end{gathered}
$$

Recall that if $X=<x_{1}, x_{2}, x_{3}, x_{4}>$ is a fuzzy trapezoidal number, then

$$
E(X)=\frac{x_{1}+2 x_{2}+2 x_{3}+x_{4}}{6},
$$

where $E(X)$ - crisp possibilistic mean value of the fuzzy number $X$.

This formula takes place if the membership function is interpreted as a (unnormalized) probability distribution density and the mathematical expectation of the corresponding random variable is considered [9].

As the object of the study, a large network was chosen, which has been operating for more than 20 years in the field of tourist and recreational services of the Irkutsk region, one of the leaders of the regional tourist market. The study involved the heads of 8 companies: three accommodation facilities (AF1 - a hotel with 160 rooms, AF2 - 30 rooms, SR3 - 201 rooms); two catering establishments (Cat1 - a restaurant for 100 seats, Cat2 - catering service); ski complex (SC); travel agency - tour operator (TO); transport company (TC).

Despite the high level of competition in the regional tourism and recreation area, the network members are trying to maintain mutually beneficial partnerships in certain areas. Hotels cooperate in the aspect of accommodating guests in case of maximum load and the impossibility to serve guests more than their actual capacity (or in the absence of available rooms of the corresponding category). Catering establishments belonging to specific accommodation facilities cooperate in the aspect of catering with other hotel companies. Joint activities are carried out related to training and advanced training of personnel, there is a movement of workers (horizontal and vertical) within the alliance. By joint efforts, the regional tourism product is being promoted in the Russian and international markets.

The initial data for building the model were obtained as a result of in-depth interviews with company leaders ( 8 experts were interviewed; the study was conducted in March of 2020). The questionnaire contained 11 questions. Experts evaluated monetary and non-monetary parameters characterizing the effectiveness of inter-organizational interaction in the tourist and recreational network (Table 1), both in 
relation to the alliance as a whole and for each of the alliance members, as of three points in time: 2020, 2015 and 2025 (forecast).

\section{RESULTS AND DISCUSSION}

Based on the answers of the respondents, the values of the variables were determined at time $t=2$ (2020), after which the missing values of the variables were calculated at times $t=1$ (2015) and $t=3$ (2025). The calculation of the variables values at moment $t=3$ was carried out according to the formulas (1-2). Since the survey of respondents was carried out only at time $t=2$ (2020), then to determine the values of the variables $\Delta S D_{i}^{1}, \Delta S D_{i j}^{1}, \Delta M I D_{i}^{1}, \Delta M I D_{i j}^{1}, \Delta P M_{i}^{1}, \Delta S T C_{i}^{1}, \Delta P P C_{i}^{1}$, $\triangle M F C_{i}^{1}$, the questionnaire used questions of the form: "Evaluate the change.... [corresponding indicator] compared to its value five years ago (2015)". In this regard, the values of the linguistic variables differed from those given in Table 2 by temporal form (the future tense has been replaced by the past). Wherein, the values of the variables at time $t=1$ (2015) were calculated using the formulas:

$$
\begin{gathered}
S D_{i}^{1}=S D_{i}^{2}-\Delta S D_{i}^{1}, S D_{i j}^{1}=S D_{i j}^{2}-\Delta S D_{i j}^{1}, \\
M I D_{i}^{1}=M I D_{i}^{2}-\Delta M I D_{i}^{1}, \\
M I D_{i j}^{1}=M I D_{i j}^{2}-\Delta M I D_{i j}^{1} \\
P M_{i}^{1}=P M_{i}^{2}-\Delta P M_{i}^{1}, S T C_{i}^{1}=S T C_{i}^{2}-\Delta S T C_{i}^{1}, \\
P P C_{i}^{1}=P P C_{i}^{2}-\Delta P P C_{i}^{1}, M F C_{i}^{1}=M F C_{i}^{2}-\Delta M F C_{i}^{1}
\end{gathered}
$$

Since we are dealing with trapezoidal fuzzy numbers, the formula was used to calculate their difference:

$$
\left(a_{1}, a_{2}, a_{3}, a_{4}\right)-\left(b_{1}, b_{2}, b_{3}, b_{4}\right)=\left(a_{1}-b_{4}, a_{2}-b_{3}, a_{3}-b_{2}, a_{4}-b_{1}\right)
$$

For fuzzy numbers, in the general case, the identities $x+y=z$ and $x=z-\mathrm{y}$ are not equivalent. Therefore, formulas (13) - (15) do not follow from formulas (1) - (3). For testing the formulated hypotheses, this is not critical, since ultimately we are interested in the dynamics of the selected indicators of the effectiveness of interorganizational relations in the network.

The values of these indicators at each separate moment of time, of course, depend on the selected formulas for the sum and difference (other known formulas can also be used), as well as on the defuzzification method, but by themselves they cannot serve as a basis for the corresponding conclusions. Further, using formulas (4-12), the values of variables were calculated that characterize the integral effectiveness of interorganizational relations in the network at different points in time at the level of individual network members (Table 6) and at the level of the network as a whole (Table 7).

The results obtained allow us to draw the following conclusions:
1. Most organizations have a positive trend in the level of satisfaction. All organizations show a pronounced positive dynamics in the degree of satisfaction with interaction with counterparties within the alliance. All companies in the alliance showed a positive trend in the degree of satisfaction of their counterparties with interaction with them. There is a very weak tightness of the direct relationship between the dynamics of the average degree of satisfaction of individual companies with interaction with counterparties and the dynamics of the average degree of satisfaction of counterparties with interaction with them. Therefore, in the long term, the effectiveness of interorganizational relations is growing, the dual relations of most members of the alliance are improving, while they are optimistic about the future development of relations, which, namely, empirically confirms the provisions of the interorganizational cooperation concept.

2. A pronounced negative dynamics of the overall and average degree of influence of the agents of the alliance was found, while over time, all members of the alliance showed a shift in the degrees of mutual influence in favor of the alliance, i.e. presence in the alliance leads to certain restrictions on the freedom of decision-making by individual members. A high tightness of feedback was revealed between the dynamics of the average degree of satisfaction with the interaction with counterparties of individual companies and the dynamics of the degree of mutual influence between the companies and the alliance. Wherein, the dynamics of the degrees of mutual influence of individual members of the alliance with counterparties is multidirectional. Agents are ready to sacrifice the power of their influence in order to obtain additional preferences (material and/or nonmaterial) from participation in the alliance. Therefore, the presence in the alliance, although it leads to the loss of the power of influence of its individual members, however, these losses are offset by the benefits obtained as a result of increasing the efficiency of interorganizational interaction.

3. A pronounced negative dynamics of the total and average costs of the members of the alliance for personnel training, product promotion and management functions was found, which indicates the effectiveness of interorganizational relations in the monetary aspect.

4. There is a high tightness of feedback between the dynamics of the average degree of mutual satisfaction of agents with counterparties and indicators characterizing the stability of relations between agents in the alliance. There is a high tightness of feedback between reducing agents' costs for performing managerial functions and indicators 
characterizing the stability of relations in the alliance, as well as between reducing the total costs of agents for personnel training, product promotion and performance of managerial functions and indicators characterizing the stability of the alliance relationship. Therefore, perception of the stability of relations is significantly influenced not only by the dynamics of the average degree of mutual satisfaction of agents with counterparties, but also by the dynamics of some types of costs of the alliance members. There is a high tightness of the feedback between the dynamics of the average

Table 6. Integral indicators of the effectiveness of interorganizational relations (the level of individual network members) (fragment of the table)

\begin{tabular}{|c|c|c|c|c|c|c|}
\hline$i_{i}$ & 1 & 2 & 3 & $\ldots$ & 7 & 8 \\
\hline$A P S D_{i}^{1}$ & 5.8 & 11.7 & 8.5 & $\ldots$ & 1.9 & 4.5 \\
\hline$A_{P S D_{i}^{2}}$ & 23.5 & 22.0 & 23.2 & $\ldots$ & 20.2 & 13.5 \\
\hline$A P S D_{i}^{3}$ & 31.0 & 25.0 & 26.2 & $\cdots$ & 25.3 & 23.3 \\
\hline$\overline{A P S D}_{i}^{1}$ & 8.5 & 5.7 & 4.3 & $\ldots$ & 10.3 & 8.8 \\
\hline$\overline{A P S D}_{i}^{2}$ & 26.3 & 24.8 & 24.7 & $\ldots$ & 20.5 & 13.3 \\
\hline$\overline{A P S D}_{i}^{3}$ & 29.3 & 30.8 & 29.2 & $\ldots$ & 32.3 & 19.3 \\
\hline $\operatorname{APSD}_{i}^{1}+\overline{A P S D}_{i}^{1}$ & 14.3 & 17.3 & 12.8 & $\cdots$ & 12.2 & 13.3 \\
\hline$\overline{A P S D}_{i}^{2}+\overline{A P S D}_{i}^{2}$ & 49.8 & 46.8 & 47.8 & $\cdots$ & 40.7 & 26.8 \\
\hline$A P S D_{i}^{3}+\overline{A P S D}_{i}^{3}$ & 60.3 & 55.8 & 55.3 & $\cdots$ & 57.6 & 42.6 \\
\hline$A M I D_{i}^{1}$ & 5.0 & 0.0 & 1.2 & $\cdots$ & -0.3 & 0.1 \\
\hline$A M I D_{i}^{2}$ & 0.0 & 5.2 & 5.3 & $\ldots$ & -8.1 & -4.4 \\
\hline$A M I D_{i}^{3}$ & -8.3 & 6.7 & 8.3 & $\ldots$ & -3.1 & -1.4 \\
\hline$A F R_{i}^{2}$ & 7.0 & 7.0 & 3.0 & $\cdots$ & 3.0 & 3.0 \\
\hline$A E Q R_{i}^{2}$ & 5.0 & 5.0 & 3.0 & $\cdots$ & 3.0 & 1.5 \\
\hline$A S T R_{i}^{2}$ & 7.0 & 7.0 & 7.0 & $\ldots$ & 5.0 & 7.0 \\
\hline$A R R_{i}^{2}$ & 5.0 & 7.0 & 3.0 & $\cdots$ & 7.0 & 7.0 \\
\hline$A L R_{i}^{2}$ & 8.8 & 8.8 & 7.0 & $\cdots$ & 7.0 & 7.0 \\
\hline$A P R_{i}^{2}$ & 5.0 & 5.0 & 3.0 & $\cdots$ & 5.0 & 3.0 \\
\hline$A R Q_{i}^{2}$ & 37.8 & 39.8 & 26.0 & $\cdots$ & 30.0 & 28.5 \\
\hline
\end{tabular}

Table 7. Integral indicators of the interorganizational relations effectiveness (the network level as a whole)

\begin{tabular}{|c|c|c|c|}
\hline$t$ & 1 & 2 & 3 \\
\hline$A S D^{t}$ & 8.8 & 14.8 & 23.8 \\
\hline$A P S D^{t}$ & 145.0 & 362.7 & 466.0 \\
\hline$A M I D^{t}$ & 0 & -25.0 & -44.2 \\
\hline$A P M^{t}$ & 34.0 & 22.0 & - \\
\hline$A S T C^{t}$ & 45.7 & 26.7 & - \\
\hline$A P P C^{t}$ & 87.8 & 68.8 & - \\
\hline$A M F C^{t}$ & 56.3 & 39.8 & - \\
\hline$A F R^{2}$ & - & 38.0 & - \\
\hline$A E Q R^{2}$ & - & 32.5 & - \\
\hline$A S T R^{2}$ & - & 53.8 & - \\
\hline$A R R^{2}$ & - & 50.0 & - \\
\hline$A L R^{2}$ & - & 59.5 & - \\
\hline$A P R^{2}$ & - & 36.0 & - \\
\hline$A Q R_{i}^{t}$ & - & 269.8 & - \\
\hline
\end{tabular}


degree of influence of the agents of the alliance and the indicators characterizing the fairness of the relations of agents in the alliance.

\section{REFERENCES}

[1] M. Yu. Sheresheva, Methodology for studying network forms of business organization. In: Higher School of Economics Pbl. (2014).

[2] Y. Wang, D. R. Fesenmaier, Collaborative Destination Marketing: A Case Study of Elkhart County, Indiana. In: Tourism Management, 28(3) (2007) pp. 863-875. DOI: https://doi.org/10.1016/j.tourman.2006.02.007.

[3] K. Mason, P. Doyle, V. Wong, Market orientation and quasi-intergration: Adding value through relationships. In: Industrial Marketing Management, 35 (2006) pp. 140-155. DOI: https://doi.org/10.1016/j.indmarman.2005.01.005.

[4] A. Lemmetyinen, F. M. Go, The Key Capabilities Required for Managing Tourism Business Networks. In: Tourism Management, 30(1) (2009) pp. 31-40. DOI: https://doi.org/10.1016/j.tourman.2008.04.005.

[5] S. Nordin, B. Svensson, Innovative Destination Governance: The Swedish Ski Resort of Åre. In: The International Journal of Entrepreneurship and Innovation, 8(1) (2007) pp. 53-66. DOI: https://doi.org/10.5367/000000007780007416.

[6] P. Beritelli, Cooperation among Prominent Actors in a Tourist Destination, Annals of Tourism Research, 38(2) (2011) pp. 607-629. DOI: https://doi.org/10.1016/j.annals.2010.11.015.

[7] A. Walter, T. A Muller, G. Helfert, T. Ritter, Functions of industrial supplier relationships and their impact on relationship quality. In: Industrial Marketing Management, 23 (2003) pp. 159-169. DOI: https://doi.org/10.1016/S00198501(02)00230-4.

[8] N. Rubtsova, K. Solodukhin, Conceptual model for assessing the effectiveness of inter-organizatinal relations in the tourism network. In: E3S Web of Conferences, 1 (2020) 05002. DOI: DOI: https://doi.org/10.1051/e3sconf/202020805002.

[9] E. A. Luengo, Fuzzy mean-variance portfolio selection problems, AMO-Advanced Model. In: Optim, 12(3) (2010) pp. 399-410. DOI: https://doi.org/10.1016/j.camwa.2010.10.039. 